\title{
Thyroid function in women with polycystic ovary syndrome
}

\author{
Bharti Patidar, Rekha Sapkal*
}

Department of Obstetrics and Gynecology, People's University, Bhopal, Madhya Pradesh, India

Received: 05 February 2021

Accepted: 20 February 2021

\section{*Correspondence:}

Dr. Rekha Sapkal,

E-mail: uttamsapkal@yahoo.com

Copyright: () the author(s), publisher and licensee Medip Academy. This is an open-access article distributed under the terms of the Creative Commons Attribution Non-Commercial License, which permits unrestricted non-commercial use, distribution, and reproduction in any medium, provided the original work is properly cited.

\section{ABSTRACT}

Background: This study aimed to assess the serum thyroid stimulating hormone (TSH) levels in women with polycystic ovary syndrome (PCOS), and its variation with obesity, insulin resistance and LH:FSH ratio.

Methods: This was a facility based cross sectional study conducted for a period of 18 months on a total of 165 females with PCOS diagnosed based on Rotterdam 2003 criteria. A thorough history and clinical and anthropometric examination was conducted for all females. USG abdomen and serum TSH levels and fT4 were also done and the findings were recorded on questionnaire.

Results: Subclinical hypothyroidism was documented in $17 \%$ females with PCOS. No statistically significant difference in mean values of LH:FSH ratio, insulin resistance, and obesity parameters were noted among euthyroid and subclinical hypothyroid females with PCOS $(\mathrm{p}>0.05)$. TSH levels in present study showed a statsitcally significant positive correlation with BMI.

Conclusions: The proportions of thyroid disorders are higher in females with PCOS and they both may present with various similar clinical features. BMI in females with PCOS has significant positive correlation with TSH levels. However, it is not clear whether thyroid dysfunction has significant effect on insulin resistance.

Keywords: Thyroid dysfunction, PCOS, Insulin resistance, Obesity, LH:FSH ratio

\section{INTRODUCTION}

Polycystic ovarian syndrome (PCOS) is one of the most common endocrine disorders affecting women of reproductive age group, and account for a majority of cases of hirsutism, menstrual disturbances and anovulatory infertility. Apart from these features associated with PCOS include insulin resistance, obesity, hypertension, nonalcoholic steatohepatitis (NASH) and, also metabolic syndrome. ${ }^{1,2}$ Most widely accepted criteria for diagnosis of PCOS is Rotterdam criteria. ${ }^{1}$

The prevalence of PCOS has recently been shown up to $18 \%$ with current Rotterdam diagnostic criteria. ${ }^{3}$ This increase in prevalence of PCOS has been attributed to increase in prevalence of obesity and metabolic syndrome in general population. ${ }^{4}$
Thyroid disorders are the commonest disease of endocrine system worldwide, and the reported prevalence of overt and subclinical hypothyroidism range from 3.5$4.2 \%$, and $8.02-19.3 \%$ respectively. ${ }^{5,6}$ Though the etiopathogenesis of thyroid disorders as well as PCOS is completely different, but they have certain common manifestations. Insufficient supply of thyroid hormones at the peripheral tissues have been associated with alteration in metabolic processes in the body. ${ }^{7}$ At one end, thyroid dysfunctions are associated with increased ovarian volume and cystic changes and at other end it has been documented that thyroid dysfunction are more common among females with PCOS as compared to general population. ${ }^{7-10}$

Their coexistence may influence the clinical presentation of each other and hence also has a potential to affect the course of disease and management. The present study 
was thus undertaken to assess the serum thyroid stimulating hormone (TSH) levels and Ft4 level in women with PCOS, and its variation with obesity, insulin resistance and LH:FSH ratio.

\section{METHODS}

The present cross-sectional study was conducted at obstetrics and gynecology department of tertiary care centre Bhopal for a period of 18 months i.e., from May 2018 to October 2019 on a total of 165 females with PCOS. The inclusion criteria were all the females diagnosed as PCOS based on Rotterdam 2003 criteria and belonging to age group of 15 to 45 years. ${ }^{1}$

\section{Rotterdam 2003 criteria for diagnosis of PCOS}

PCOS is diagnosed if at least 2 of 3 are present: Oligomenorrhoea/amenorrhoea (ovulatory dysfunction), clinical or biochemical signs of androgen excess, polycystic ovaries at ultrasound scan (at least one ovary $>10 \mathrm{cc}$ volume, and/or at least one ovary with $>12$ follicles of size $2-9 \mathrm{~mm}$.

Women with other causes of anovulation and/or hyperandrogenism e.g., adrenal hyperplasia, adrenal hyperandrogenaemia, Cushing's disease, virilizing tumor, hysterectomized women, ovarian tumor, premature ovarian failure, hyperprolactinemia, women on medications that affect menstrual cycles such as hormonal preparations, lithium, domperidone etc. women not willing to participate were excluded from study.

After obtaining ethical clearance from institute's ethical committee, all the females fulfilling the inclusion and exclusion criteria were enrolled in study and written consent was obtained from them. A thorough history was taken including age, age at menarche, detailed menstrual history, excessive hair, acne, weight gain, history of PCOS in mother/sibling, drug intake (hormonal), family history of diabetes, etc and entered in questionnaire. Detailed history regarding menstrual pattern, acne, alopecia, hirsutism was noted. Height, waist circumference, hip circumference and weight of all the participants were obtained and they were classified as having obesity based on the following features-waist circumference greater than $80 \mathrm{~cm}$, WHR greater than 0.8 , BMI: overweight: $23 \mathrm{~kg} / \mathrm{m}^{2}$ or higher; obese $25 \mathrm{~kg} / \mathrm{m}^{2}$ or higher, (waist circumference; WHR:BMI).

Vitals such as pulse, blood pressure and respiratory rate was noted for all the patients. Secondary sexual characters were assessed for all females and androgen status was assessed for presence of hirsutism, acne, temporal recession of hair etc. Evidence of insulin resistance (acanthosis nigricans) if any was also looked for and findings were noted in questionnaire. Further USG was conducted for all the females to study PCO morphology and serum TSH levels and $\mathrm{Ft} 4$ were estimated. The normal range for TSH levels was 0.25-5 $\mathrm{mIU} / \mathrm{Ml}$ whereas for fT4 9-19 pmol/L.

\section{Statistical analysis}

Data was compiled using Ms excel and analysed using SPSS software version 20. Data was grouped and expressed as frequency and percentage whereas numerical data was expressed as mean \pm SD. ANOVA test was applied to assess the difference in mean values among females with different thyroid status.

\section{RESULTS}

The present study included a total of 165 females with PCOS diagnosed based on Rotterdam criteria.

Table 1: Distribution of study participants according to baseline variables.

\begin{tabular}{|c|c|c|c|}
\hline \multicolumn{2}{|c|}{ Baseline variables } & $\begin{array}{l}\text { Frequency } \\
(n=165)\end{array}$ & $\%$ \\
\hline \multirow{3}{*}{ Age (years) } & $\leq 20$ & 44 & 26.7 \\
\hline & $21-30$ & 113 & 68.5 \\
\hline & $>30$ & 8 & 4.8 \\
\hline \multirow{2}{*}{ Residence } & Rural & 40 & 24.2 \\
\hline & Urban & 125 & 75.8 \\
\hline \multirow{5}{*}{ BMI $\left(\mathrm{kg} / \mathrm{m}^{2}\right)$} & $\begin{array}{l}\text { Underweight } \\
(<18.5)\end{array}$ & 17 & 10.3 \\
\hline & $\begin{array}{l}\text { Normal } \\
(18.5-22.9)\end{array}$ & 73 & 44.2 \\
\hline & $\begin{array}{l}\text { Overweight } \\
(23-24.9)\end{array}$ & 25 & 15.2 \\
\hline & $\begin{array}{l}\text { Obese I (25- } \\
29.9)\end{array}$ & 48 & 29.1 \\
\hline & $\begin{array}{l}\text { Obese II (30- } \\
34.9)\end{array}$ & 2 & 1.2 \\
\hline \multirow{2}{*}{$\begin{array}{l}\text { Waist } \\
\text { circumference } \\
(\mathrm{cm})\end{array}$} & $\leq 80$ & 63 & 38.2 \\
\hline & $>80$ & 102 & 61.8 \\
\hline \multirow{2}{*}{$\begin{array}{l}\text { Waist hip } \\
\text { ratio }\end{array}$} & $\leq 0.85$ & 52 & 31.5 \\
\hline & $>0.85$ & 113 & 68.5 \\
\hline
\end{tabular}

Mean age of females with PCOS was 23.21 \pm 4.57 years and majority of females belonged to 21 to 30 years of age (68.5\%). About $75.8 \%$ females were resident of urban area whereas only $24.2 \%$ females were resident of rural area. About $30.3 \%$ females were obese in present study with $\mathrm{BMI}>25 \mathrm{~kg} / \mathrm{m}^{2}$. Waist circumference was $>80 \mathrm{~cm}$ in $61.8 \%$ females whereas waist hip ratio $>0.85$ was observed in $68.5 \%$ females with PCOS.

In present study, USG was suggestive of polycystic morphology in $98.8 \%$ females with PCOS and one or more of the clinical features of hyperandrogenism were documented in $74.6 \%$ females i.e., acne in $68.4 \%$, excess body hairs in $46.6 \%$ and alopecia in $9.7 \%$ females. However, acanthosis was documented in $26.7 \%$ and alopecia was observed in $9.7 \%$ females with PCOS. 
Most common menstrual cycle abnormality in females with PCOS was oligomenorrhea observed in $60.6 \%$ females, followed by oligomenorrhea with hypomenorrhea observed in $14.5 \%$ females. However, menstrual cycles were regular in $6.7 \%$ females with polycystic ovarian syndrome.

Table 2: Distribution according to thyroid status.

\begin{tabular}{|lll|}
\hline $\begin{array}{l}\text { Thyroid status } \\
\text { Subclinical }\end{array}$ & $\begin{array}{l}\text { Frequency } \\
(\mathbf{n}=165)\end{array}$ & $\begin{array}{l}\text { Percentage } \\
(\%)\end{array}$ \\
\hline hypothyroid & 28 & 17 \\
\hline Euthyroid & 137 & 83 \\
\hline
\end{tabular}

Mean TSH levels in study was $2.69 \pm 1.50 \mu \mathrm{IU} / \mathrm{ml}$, mean fT4 was $12.4 \pm 2.2 \mathrm{pmol} / \mathrm{L}$. Majority of females with PCOS were euthyroid $(83 \%)$ whereas subclinical hypothyroidism was documented in $17 \%$ females. Though mean LH:FSH ratio, insulin resistance, waist hip ratio, waist circumference and BMI were higher in subclinical hypothyroid females with PCOS as compared to euthyroid females, in study documented no statistically significant difference in their mean values $(\mathrm{p}>0.05)$.

TSH levels in study showed a statsitcally significant positive correlation with BMI i.e. as BMI increased TSH levels increased $\left(\mathrm{R}^{2}=0.024, \mathrm{p}=0.048\right)$. However no statistically significant correlation of TSH levels was observed with $\mathrm{LH}: \mathrm{FSH}$ ratio, insulin resistance, waist hip ratio and waist circumference $(\mathrm{p}>0.05)$.

Table 3: Association of thyroid status with LH/FSH ratio, insulin resistance and obesity.

\begin{tabular}{|lllll|} 
Variables & Euthyroid & $\begin{array}{l}\text { Subclinical } \\
\text { hypothyroid }\end{array}$ & $\begin{array}{l}\text { T } \\
\text { test }\end{array}$ & $\begin{array}{l}\text { P } \\
\text { value }\end{array}$ \\
\hline $\begin{array}{l}\text { LH:FSH } \\
\text { ratio }\end{array}$ & $3.61 \pm 8.34$ & $4.61 \pm 5.6$ & 0.61 & 0.54 \\
\hline Homa IR & $1.55 \pm 1.23$ & $2.1 \pm 1.92$ & 1.94 & 0.05 \\
\hline WHR & $0.88 \pm 0.59$ & $0.91 \pm 0.07$ & 0.27 & 0.79 \\
\hline WC & $83.62 \pm 10.6$ & $86.06 \pm 10.8$ & 1.13 & 0.26 \\
\hline BMI & $23.1 \pm 4.49$ & $24.14 \pm 4.43$ & 1.1 & 0.28 \\
\hline
\end{tabular}

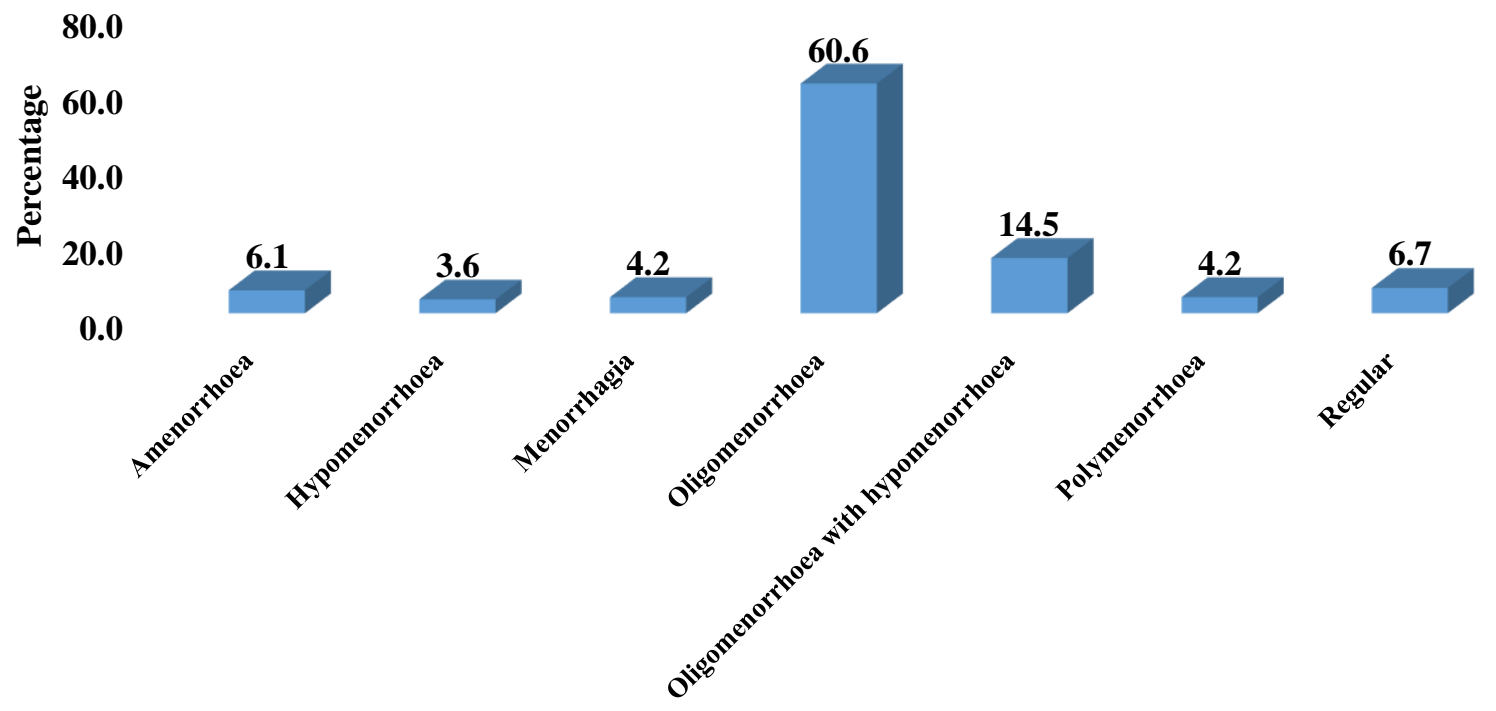

Menstrual irregularities

Figure 1: Distribution according to menstrual cycle characteristics.

Table 4: Correlation of TSH levels with $\mathrm{LH} / \mathrm{FSH}$ ratio, insulin resistance and obesity.

\begin{tabular}{|lllllll|}
\hline Variables & $\mathbf{R}$ & $\mathbf{R}^{2}$ & Adjusted $\mathbf{R}^{2}$ & SE & ANOVA & P value \\
\hline LH:FSH ratio & 0.110 & 0.012 & 0.006 & 1.620 & 1.997 & 0.160 \\
\hline Homa IR & 0.081 & 0.007 & -0.002 & 1.660 & 0.759 & 0.386 \\
\hline WHR & 0.142 & 0.020 & 0.014 & 1.616 & 3.295 & 0.071 \\
\hline WC & 0.139 & 0.019 & 0.013 & 1.614 & 3.222 & 0.075 \\
\hline BMI & 0.154 & 0.024 & 0.018 & 1.610 & 3.952 & 0.048 \\
\hline
\end{tabular}



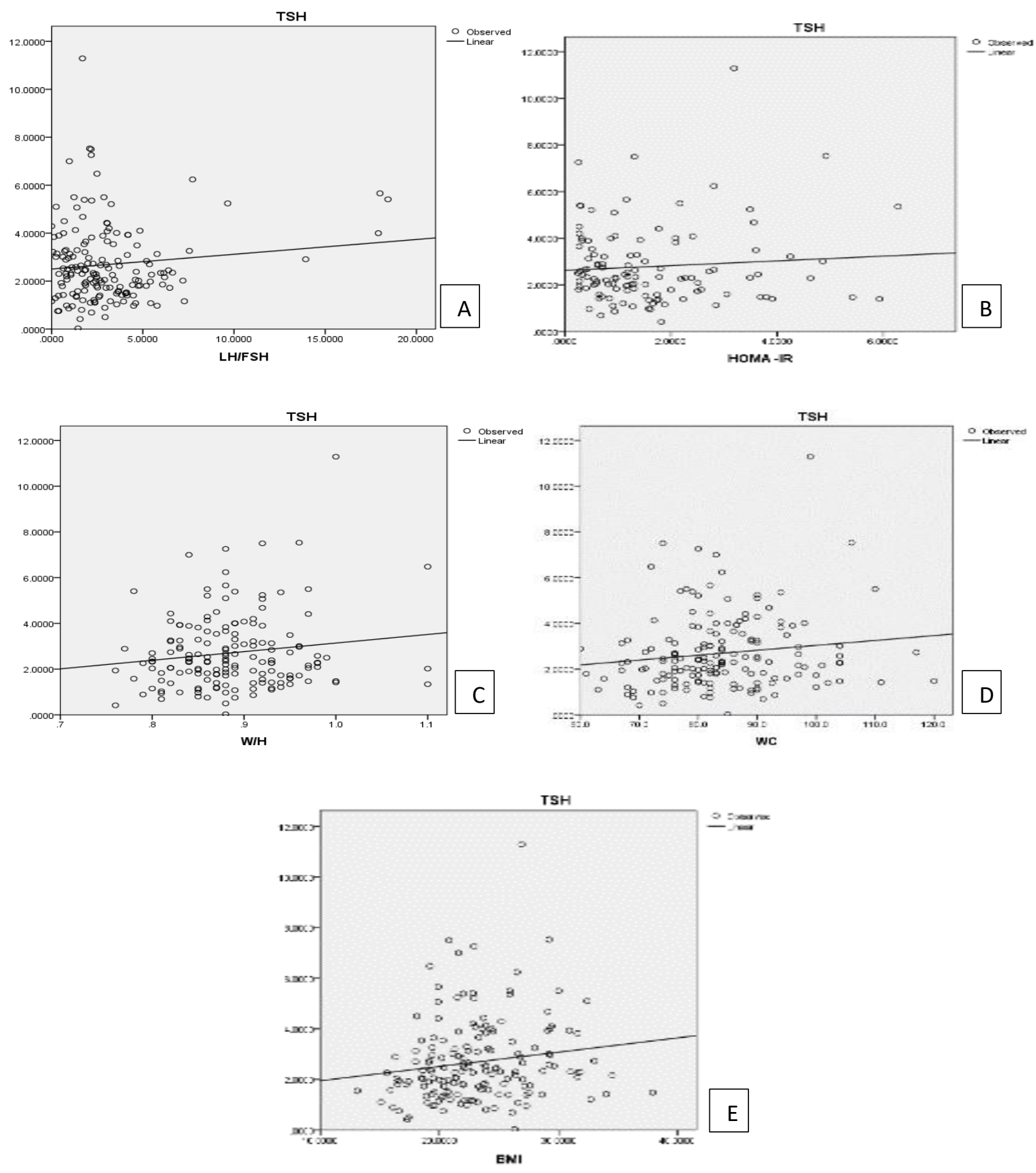

Figure 2: Correlation of correlation of TSH levels with LH/FSH ratio (A), insulin resistance (B), waist hip ratio (C), waist circumference (D) and BMI (E).

\section{DISCUSSION}

Both PCOS as well as thyroid dysfunction has certain common clinical manifestations. Apart from their important role in regulating metabolism, thyroid hormones also play important role in reproductive health. Thyroid receptors as well as TSH receptors are expressed in uterus and ovaries in females. ${ }^{11}$ PCOS is the most common disorder in females of reproductive age group. ${ }^{1}$ In present study, maximum females with PCOS belonged to 21 to 30 years of age $(68.5 \%)$ with mean age of $23.21 \pm 4.57$ years. Similar findings were reported by Goyal et al in which maximum females belonged to 2130 years of age and the mean age of females with PCOS was $26.76 \pm 6.7$ years. ${ }^{12}$ Lamberg and Abufaza et al 
documented that PCOS mainly affects women in age range of 18-35 years. ${ }^{13,14}$

The presence of obesity amongst females with PCOS is one of the classical features, though its presence is variable. It has been observed that higher BMI is associated with greater insulin resistance and hyperandrogenism. Thus, hirsutism and alopecia are one of the common features amongst obese anovulatory females. ${ }^{[15]}$ In present study, normal BMI was observed in $44.3 \%$ females whereas $30.3 \%$ females were obese whereas Waist circumference and waist hip ratio were raised in 61.8 and $68.5 \%$ females respectively with PCOS. Goyal et al also documented that females with PCOS had significantly higher body mass index (BMI) as compared to controls. ${ }^{12}$

Thyroid dysfunctions i.e., subclinical hypothyroidism was documented in $17 \%$ females. Mean TSH levels among study participants was $2.69 \pm 1.5 \mu \mathrm{IU} / \mathrm{ml}$ and mean fT4 was $12.4 \pm 2.2 \mathrm{pmol} / \mathrm{L}$. These findings were supported by Benetti-Pinto et al in which prevalence of subclinical hypothyroidism in females with PCOS was estimated to be $11.3 \%$ (mean TSH level of $6.1 \pm 1.2 \mathrm{mIU} / \mathrm{L}$ ). ${ }^{16}$ Enzevaei et al documented $25.5 \%$ prevalence of subclinical hypothyroidism in their study. ${ }^{17}$

The present study also aimed to assess the variation in LH:FSH ratio, insulin resistance, waist hip ratio, waist circumference and BMI with thyroid dysfunction. The mean values of above-mentioned variables were higher in females with thyroid dysfunction as compared to euthyroid females, but test of significance (ANOVA) observed no statistically significant difference $(p>0.05)$.

It has been postulated that hypothyroidism is associated with increased TSH and TRH levels. Increased TRH in cases with primary hypothyroidism leads to increased secretion of prolactin and TSH. This increased level of prolactin further inhibit ovulation and thereby contribute to polycystic ovarian morphology and thus can affect LH:FSH ratio. Also raised level of TSH has spill-over effect on FSH receptor and thus further contribute altered LH:FSH ratio. Increased TSH also contributes due to its spill-over effect on FSH receptors. ${ }^{18}$ However no significant correlation of thyroid dysfunction was documented with LH:FSH ratio in present study, this could be explained by small sample size or presence of higher number of cases with subclinical hypothyroidism.

However, we documented a statistically significant positive correlation between TSH levels and BMI $\left(\mathrm{R}^{2}=0.024, \mathrm{p}=0.048\right)$. Obesity is an integral part of PCOS and has been also associated with hypothyroidism. The etiopathogenesis of obesity in hypothyroidism has been attributed to activation of adipocytes in the adipose tissue which alter the milieu and increase the levels of proinflammatory markers and further contribute to insulin resistance. ${ }^{19}$ Another possible pathogenesis linking obesity and hypothyroidism has been postulated by leptin pathway. The levels of leptin are increased in obese individuals which directly act on hypothalamus and increase TRH secretion. ${ }^{20}$ Muscogiuri et al in their study documented that both adiposity and insulin resistance were significantly associated with raised TSH. ${ }^{19}$

The cause-and-effect relationship may not be visible accurately in such a small sample of sub-groups. A larger sample size would further help to provide a more validated data. A majority of women in the present study were urban and so the generalizability of the results is limited for rural women. Also, serum T3, and anti TPO antibody levels could not be assessed which could have yielded better results.

\section{CONCLUSION}

The proportions of thyroid disorders are higher in females with PCOS and they both may present with various similar clinical features. BMI in females with PCOS has significant positive correlation with TSH levels. However, it is not clear whether thyroid dysfunction has significant effect on insulin resistance.

\section{ACKNOWLEDGMENTS}

Author would like to thank to guide Dr. Rekha Sapkal (HOD OBGY). I thank her for her inimitable guidance and constant encouragement. Her immense knowledge vast experience, affection attitude was a source of constant inspiration for me.

I would like to express my grateful feeling to Dr. J. N. Modi and Dr. Gurpreet for her valuable suggestion and supervision. Thank you very much. Above all thanks almighty God for all his blessings.

\section{Funding: No funding sources}

Conflict of interest: None declared

Ethical approval: The study was approved by the Institutional Ethics Committee

\section{REFERENCES}

1. Rotterdam ESHRE/ASRM-Sponsored PCOS Consensus Workshop Group. Revised 2003 consensus on diagnostic criteria and long-term health risks related to polycystic ovary syndrome (PCOS). Human reproduction. 2004;19(1):41-7.

2. Kowalczyk K, Franik G, Kowalczyk D, Pluta D, Blukacz $Ł$, Madej P. Thyroid disorders in polycystic ovary syndrome. Euro Review Med Pharmacol Sc. 2017;21:346-60.

3. Diamanti-Kandarakis E, Dunaif A. Insulin resistance and the polycystic ovary syndrome revisited: an update on mechanisms and implications. Endocrine reviews. 2012;33(6):981-1030. 
4. Devru N, Dharmshaktu P, Kumar G, Dutta D, Kulshreshtha B. Phenotypic presentation of adolescents with overt primary hypothyroidism. J Pediatr Endocrinol Metab. 2018;31(4):415-20.

5. Unnikrishnan AG, Kalra S, Sahay RK, Bantwal G, John M, Tewari N. Prevalence of hypothyroidism in adults: An epidemiological study in eight cities of India. Indian J Endocrinol Metab 2013;17:647-52.

6. Marwaha RK, Tandon N, Ganie MA, Kanwar R, Sastry A, Garg MK et al. Status of thyroid function in Indian adults: Two decades after universal salt iodization. J Assoc Physicians India. 2012;60:32-6.

7. Sinha U, Sinharay K, Saha S, Longkumer TA, Baul SN, Pal SK. Thyroid disorders in polycystic ovarian syndrome subjects: A tertiary hospital based crosssectional study from Eastern India. Indian J Endocrinol Metab. 2013;17:304-9.

8. Benetti-Pinto CL, Berini Piccolo VR, Garmes HM, TeatinJuliato CR. Subclinical hypothyroidism in young women with polycystic ovary syndrome: An analysis of clinical, hormonal, and metabolic parameters. Fertil Steril. 2013;99:588-92.

9. Ramanand SJ, Ghongane BB, Ramanand JB, Patwardhan MH, Ghanghas RR, Jain SS. Clinical characteristics of polycystic ovary syndrome in Indian women. Indian $\mathbf{J}$ Endocrinol Metab. 2013; $17: 138-45$.

10. Janssen OE, Mehlmauer N, Hahn S, Offner AH, Gärtner R. High prevalence of autoimmune thyroiditis in patients with polycystic ovary syndrome. Eur J Endocrinol. 2004;150:363-9.

11. Escobar-Morreale HF. Polycystic ovary syndrome: definition, aetiology, diagnosis and treatment. Nature Reviews Endocrinology. 2018;14(5):270.

12. Goyal D, Relia P, Sehra A, Khandelwal D, Dutta D, Jain D, Kalra S. Prevalence of hypothyroidism and thyroid autoimmunity in polycystic ovarian syndrome patients: A North Indian study. Thyroid Res Pract 2019;16:55-9

13. Lamberg BA: Glucose metabolism in thyroid disease. Acta Med Scand. 1965;178(3):351-62.

14. AbuFaza M, Abdelazim I, Purohit P, Shikanova S, Zhurabekova G, Karimova B et al. The diagnosis and the reproductive and metabolic consequences of polycystic ovary syndrome. J Obstet Gynecol Investig. 2018;1:67-73.

15. Vignesh JP, Mohan V. Polycystic ovary syndrome: A component of metabolic syndrome? J Postgrad Med. 2007;53:128-34

16. Benetti-Pinto CL, Berini Piccolo VR, Garmes HM, TeatinJuliato CR. Subclinical hypothyroidism in young women with polycystic ovary syndrome: An analysis of clinical, hormonal, and metabolic parameters. Fertil Steril. 2013;99:588-92.

17. Enzevaei A, Salehpour S, Tohidi M, Saharkhiz N. Subclinical hypothyroidism and insulin resistance in polycystic ovary syndrome: is there a relationship? Ira J Reprod Med. 2014;12(7):481.

18. Singla R, Gupta Y, Khemani M, Aggarwal S. Thyroid disorders and polycystic ovary syndrome: An emerging relationship. Indian J endocrinol metab. 2015;19(1):25.

19. Muscogiuri G, Sorice GP, Mezza T, Prioletta A, Lassandro AP, Pirronti T et al. High-normal TSH values in obesity: Is it insulin resistance or adipose tissue's guilt? Obesity (Silver Spring). 2013;21:1016.

20. Duntas LH, Biondi B. The interconnections between obesity, thyroid function, and autoimmunity: The multifold role of leptin. Thyroid. 2013;23:646-53.

Cite this article as: Patidar B, Sapkal R. Thyroid function in women with polycystic ovary syndrome. Int J Reprod Contracept Obstet Gynecol 2021;10:929-34. 